\title{
Engineering REU Sites: Designing for Appropriate and Valuable Summer Educational Experiences
}

\author{
Kevin Sutterer, Martin Brenny, J. David Pirnia, \\ Michelle Woodward, Robert Houghtalen, and Jim Hanson
}

Department of Civil Engineering, Rose-Hulman Institute of Technology

\begin{abstract}
The National Science Foundation (NSF) provides funds for summer Research Experience for Undergraduates (REU) programs with the aim to provide appropriate and valuable educational experiences for undergraduate students through research. Through effective REU programs, talented undergraduate students should be retained and attracted to productive careers in teaching and university research. The "products" of REU programs are the students. They should exit a summer REU program with a clear understanding of what researchers do, how research impacts society, what their options are in pursuing research and higher education, and a toolbox of skills that better prepare them to succeed in related careers. A summer REU program should thus be a research "training camp" to prepare students to make informed choices about a career in teaching and research, and to prepare students for success in those fields, if that is their career choice. As such, the summer REU experience must feature three key parts:
\end{abstract}

- Leadership of meaningful and valued research

- Formal learning about graduate studies, the craft of research, and leadership

- A positive and supportive community

The student experience must be understood in order to plan the three key parts of the REU program. Balance between challenging work, formal learning, daily interaction with mentors, enriching trips, and a pleasant social setting is crucial. Similarly, the research mentor (faculty, usually) must consider their role in all three parts of a successful REU program. Passion for the work, faith in the process, collegiality with the students, and commitment to success are contagious and thus essential. Mentors must understand that quality time is not a substitute for quantity of time when students are learning on a tight schedule, and that a close student/mentor relationship on multiple levels should be sought. Finally, the support infrastructure and research setting are essential considerations. This should consist of support personnel that respond quickly; attentive and engaged clients; a varied research experience that includes theory, field, lab, and modeling work; and residential living among a research community. The paper concludes with guidelines for planning successful REU programs, including examples and assessment schemes to foster program success.

\section{Introduction}

National Science Foundation (NSF) sponsors Research Experience for Undergraduates (REU) programs in the form of REU Sites or Supplements. REU Supplements typically support one or two undergraduates working on an existing or new NSF award while REU Sites typically sponsor groups of 6 to 12 students in a planned, independently granted program (NSF, 2004).

"Proceedings of the 2005 American Society for Engineering Education Annual Conference \& Exposition Copyright . 2005, American Society for Engineering Education” 
An effective REU program, however, must set up a win-win scenario that considers not only NSF's needs, but also those of the other stakeholders. Fundamentally, for long term success, a program must balance the needs of NSF, the student participants, the faculty mentor, the program administration team, and, from a long range perspective, society.

This paper is part of a research work in progress on developing and managing a high quality REU site. Part of that effort is to understand the different perspectives of REU participants and to identify characteristics of programs that address the perspectives of all of the stakeholders. In an effort to disseminate preliminary findings of this study, the paper examines stakeholders' perspectives, identifies key factors in program success, and suggests guidelines for fostering exceptional REU Site. The authors are comprised of an REU site administrator, an REU faculty mentor, three students who participated in REU programs (one at Rose-Hulman and two off campus) and a department chair who is supporting administration of an REU program.

\section{National Science Foundation Perspective}

Part of NSF's Program Description for REU grants (NSF, 2004) states: "The REU program, through both Supplements and Sites, aims to provide appropriate and valuable educational experiences for undergraduate students through research participation. REU projects involve students in meaningful ways in ongoing research programs or in research projects specially designed for the purpose. REU projects feature high-quality interaction of students with faculty and/or other research mentors and access to appropriate facilities and professional development opportunities. Active research experience is considered one of the most effective ways to attract talented undergraduates to and retain them in careers in science and engineering, including careers in teaching and educational research."

NSF thus expects REU programs to feature high quality interaction between students and faculty, access to appropriate facilities, professional development opportunities, and planning and facilitation to attract talented undergraduates to careers in science and engineering, including teaching and research. NSF also emphasizes that such programs can play a key role in encouraging individuals from underrepresented groups to pursue such careers, an essential need to improve diversity in the math, science and engineering community.

Fundamentally, the "products" of REU programs are the students. Through REU funding, NSF is investing federal funds in the future of the engineering, math and science community, and in society at large. Thus, the first and primary goal of successful REU programs must be to produce students who have had a quality research experience featuring all four of the above components and who are better prepared to make informed choices about their future in engineering, math or science.

\section{Faculty Mentor Perspective}

Although REU programs may feature professionals other than faculty working as research mentors, faculty are likely the most common research mentors in REU programs. For this reason, and for others noted later, the focus here will be on faculty mentors, although the insights could be applied to non-faculty mentors as well. ASEE sponsored a session at its 2004 Annual Meeting addressing pre-graduate school research. One of the papers for that session (Kukreti, 2004) specifically addressed REU programs and their administration, while another (Eisenman

"Proceedings of the 2005 American Society for Engineering Education Annual Conference \& Exposition Copyright . 2005, American Society for Engineering Education” 
and List, 2004) reported on undergraduate research programs (not REU's) with a specific emphasis on faculty and student perspectives. Our own experiences and insights from discussions with other REU research mentors supplements this information.

Most faculty members' greatest need in the conduct of their work is time, followed closely by support and recognition. Untenured assistant professors can easily justify 70+ hour work weeks during the academic year, and anecdotally, successful tenured faculty report their workload and time commitment increase with promotion rather than decrease. One of this paper's co-authors maintained formal time sheets as a personal exercise during key points in his academic career to compare with his work effort as a consultant. He found that during the academic year, 60 to $90+$ hour weeks were typical, and that effective work effort when classes were not in session required at least 50+ hours per week on average. Thus, when balanced with personal factors such as family and personal travel, with research project commitments, and with a typically heavier schedule of business travel, time is a premium for faculty during summer REU's. Faculty who cannot provide significant time to the REU program should not be mentors.

Support for faculty refers to commitment of institute resources to their work. This includes technical personnel, secretarial assistance, travel support, and supplies. Faculty mentors must have access to this support to be able to effectively guide their students through a research project. Faculty at institutes which are unable or unwilling to provide this support as a supplement to the NSF funding will struggle to be effective as an REU mentor.

Recognition refers to how the institute responds to the faculty efforts in the REU. If being an REU mentor is valued by the department chair, dean, and other administrators, the faculty member is more likely to be effective. If, on the other hand, the administration does not value the REU mentor's role, or even assigns it negative value, the REU mentor's effectiveness will be diminished. At most institutes, faculty scholarship is carefully scrutinized. At $\mathrm{PhD}$ granting institutes, research work completed by MS students is often given lesser value, so research activities of REU students may not even be a consideration in faculty recognition. REU programs at some research institutes are considered good tools for recruiting quality students, so faculty may be recognized for their role in recruiting. For those faculty who work in REU programs and stick with it, the service aspect of the mentor/student relationship tends to be the most important. The institute may thus recognize the faculty member's work as service rather than scholarship, and this may be sufficient for some faculty.

Implied in the above discussion about time, support, and recognition is the crucial role the institute's leadership plays in successful REU programs. Faculty mentors who are passionate about REU experiences may be able to overcome lack of time, support and recognition, but at great personal cost. Typical faculty mentors, on the other hand, must be enthusiastically supported by their leadership through recognition of their time commitment and provision of reasonable support to their effort. Thus, the institute leadership is a stakeholder in the REU and their needs must be considered for a successful REU program. Department and institute leadership seek to elevate scholarship in their programs, to enhance the educational needs of students, and to foster the success of their tenure-track faculty. Like the faculty mentors, department and institute leadership may also consider mentoring a part of their fundamental mission.

"Proceedings of the 2005 American Society for Engineering Education Annual Conference \& Exposition Copyright . 2005, American Society for Engineering Education” 


\section{Students' Perspective}

From students' perspective, the needs when considering whether to apply to REU programs are pretty clear. They need acceptable immediate income, experience in an area of interest, and enhancement of their opportunities for graduate school. After students have identified REU programs that appear to provide these three components, they can move on to other needs, such as location, community, and their role in a specific program, to help them make a final choice of programs. However, once students join an REU program, they quickly discover other factors that can play a major role in their satisfaction with the experience, and thus potentially with their prospect of entering graduate studies. Our three student authors compiled the information summarized in Table 1, which depicts some of these factors and their significance to the students.

\section{Key Factors in Program Success}

NSF emphasizes talented students, interaction with faculty, appropriate facilities, and professional development. However, examination of the perspectives of faculty, administration, and students discussed above shows that successful REU programs are not that simple. In fact, we have found that both students and faculty who report positive outcomes from REU programs first describe the relationships they developed among their community. We believe that successful REU programs first emphasize the relationships between students, faculty, staff, and the administration. If the students are a carefully integrated part of a research community, program planning can then focus on providing the students with valued and meaningful work. Finally, it is crucial that learning occurs throughout the program. These three factors are thus key to program success:

- Leadership of meaningful and valued research

- Formal learning about graduate studies, the craft of research, and leadership

- A positive and supportive community

Those who are planning an REU grant proposal would do well to give serious consideration to addressing these key factors while addressing NSF's needs. These are discussed further below.

To understand the role researchers play in society, students must experience and understand how their work is valued and can be important to helping society. This must begin during the recruiting process. Students must understand they are valued by their summer "employer." This should be reflected in how recruiting is conducted, and in the payment and benefits offered to the students. Once the students arrive at the program, whether the students play a small role in a bigger project, or lead their own project, they need to understand their value. Students must not merely observe quality research being done, but rather should do it. A part of doing valued work is being challenged. Thus, students should be challenged to expand their ability to do independent work, take charge of a problem, explore new knowledge and discover solutions. Finally, from the very beginning, students must be able to see where their work is leading. They must have a reachable objective in sight.

With respect to valuing student research, the role of a client is important. For some REU projects, the client may be an outside agency or professional that interacts with the student in the

"Proceedings of the 2005 American Society for Engineering Education Annual Conference \& Exposition Copyright . 2005, American Society for Engineering Education” 
completion of their work. In most REU's, the closest the students get to having a client is their faculty mentor. Either way, the students must feel that quality work is valued by their client, and the faculty, outside agency, or professional must be clear about this. Of course, ultimately, society is the students' real client, but students do not often have the chance for timely feedback from society.

Student research cannot be done without ready and willing support from mentors and the institute. Ready and willing support includes advance preparation and planning by the faculty mentor. A plan for working with the student in a way that is fruitful for the faculty and student must be developed in advance. The importance of this effort on the part of the only party (the faculty mentor) who can truly do this planning cannot be overstated. With respect to institute support, NSF expects the students to have access to appropriate facilities. Appropriate facilities will include access to literature, suitable equipment, and technical expertise. Since most REU student work will not be PhD-level work, suitable equipment may consist merely of a desktop computer, software and basic laboratory space. Thus, major university research equipment need not be a factor in students' research as long as their project is appropriate for the equipment available on campus or through off campus partnerships.

Learning is a fundamental aspect of REU's. In addition to the learning implied by NSF's expectation of professional development for the students, faculty and students recognize that research is just another type of learning, albeit much more independent than formal learning. The most crucial learning that occurs during REU's is through the mentor/student relationship, and the role of the mentor and their position is key. Though there are many career opportunities to do research, the most visible research career to students is in academia. Thus, while students must be able to see that non-academic research opportunities are available to them, they are best mentored by engaged, caring, and sincerely committed faculty. Successful REU programs must feature mentors, preferably faculty, who are available, interested, and enthusiastic.

Beyond the primary mentor-facilitated learning, planned learning should also feature experiential learning through tours, trips, and visits with other professionals. Formal instruction in a classroom setting that is more familiar to students and also helpful for "pushing" a body of necessary information quickly is also appropriate. NSF's guideline that the students' experiences include professional development could be partly fulfilled through formal learning. In particular, professional development in the area of leadership seems appropriate preparation for a career in research. Thus, as a minimum, formal planned learning on conducting research and in areas related to leadership is appropriate.

As noted earlier, many of the positive comments about REU programs from both faculty and students have to do with the relationships that have developed. Creation of a community of learner/researchers is fundamental to REU success. It is most appropriate for students to be housed together or with other research cohorts near or on campus. Early in the REU program, students should be encouraged to discover together the town and region where they are working, to become involved in outside activities with their colleagues, and to try new things. Students must be able to work with others in a lab or office space that permits spontaneous interaction and collegiality. Students and mentors must spend time together not only in meetings about their projects, but also over lunch, while working out, on trips, and at mentors' homes. Cookouts,

"Proceedings of the 2005 American Society for Engineering Education Annual Conference \& Exposition Copyright . 2005, American Society for Engineering Education" 
lunch time seminars, field trips, and social events should be common in the first few weeks of an REU, and sprinkled throughout the duration. Through this community, students will discover that researchers are just regular folks trying to do extraordinary work, that the mentors really care about their success, and that they are valued.

In summary, we propose the following guidelines for planning an effective REU.

- To assure meaningful research:

○ research work that is reasonable, challenging, multi-faceted, and well defined

$\circ$ experience in the entire research process from problem definition to publication, even if for part of a larger project

$\circ$ an organized research schedule with intermediate deliverables/benchmarks to assure a productive summer experience and a completed project

- Planned learning to prepare students to succeed in a research career:

$\bigcirc$ training on how to conduct successful research

○ leadership and ethics training

o professional activities off campus

$\bigcirc$ training in making choices about graduate school

$\circ$ visits to other universities

- To simulate a positive graduate school community:

$\circ$ engaged and committed faculty mentors

○ a flexible work schedule

- lodging in a community of cohorts, preferably on campus

- non-academic interaction with faculty, other research mentors, and institute administrators

o some planned extracurricular activities in the region

- To attract quality students:

$\circ$ stipends that are competitive with traditional summer internship positions

○ a well organized and responsive recruiting process

\section{Example REU Program}

At Rose-Hulman Institute of Technology (RHIT), the Math Department has facilitated a successful NSF REU program for 14 years. The Engineering Forensics Research Institute (EFRI) REU at RHIT just completed its inaugural summer, having learned from the success of the Math REU, from PI's for REU's at other sites in the U.S., and through study of the success of other types of summer student programs. The EFRI REU seeks to simulate as closely as possible the graduate school experience. A summary of the EFRI REU is provided below as an example demonstrating some of the characteristics of successful REU's.

The EFRI REU features real projects for outside clients identified during the academic year prior to the summer program. The program favors projects that may not be popular or easily fundable at major research institutes, but that can have a significant impact on society and that include a client who is passionate about the project's success. The project is selected and tailored so it can be completed in our facilities by a team of 2 to 4 students, from problem definition to final report, within our eight week program. Projects must be multi-faceted, including at least modeling or theory and lab or field data collection. Students interact regularly with their client, including a final presentation. We solicit and offer more projects than the expected number of

"Proceedings of the 2005 American Society for Engineering Education Annual Conference \& Exposition Copyright . 2005, American Society for Engineering Education”" 
research teams so students can choose their project and team within the first day of arrival. Students are expected to wrap up their project after returning to their home campus with a publishable work.

Recruiting of students begins in January, so we try to have at least some projects identified early in the program to assist recruiting. We know that students are applying to multiple REU's, so we are prepared for comparison to other programs and honestly highlight the things that make our program unique, and acknowledge features we do not include that other programs may offer. The EFRI team is very concerned that our students come because they really want to be here, so if we lose a prized recruit to another program, we consider it a success for the student, which is NSF's ultimate goal. EFRI hopes to have its team of eight students under contract by early April, if possible.

The EFRI REU includes a 20+ hour short course that teaches how to conduct research (Booth et al. 2003), leadership training (Covey, 1989), client relations (Block, 2000), forensic engineering (Lewis, 2003), and failure case studies by guest speakers and faculty. The short course also includes modules on selecting graduate schools and about academic life in general. Students receive a book on conducting quality research (Booth et al. 2003) and a course notes binder as a part of the short course. In 2004, EFRI made trips to Chicago for site tours and to visit with forensic expert and 9/11 investigator Dr. Gene Corley, Indianapolis to visit tornado-damaged sites and to meet clients, Purdue University to visit the graduate school and meet 9/11 investigator Dr. Mete Sozen, and University of Illinois at Urbana-Champagne for a graduate school visit. Because RHIT is an undergraduate-focused institute, there are no concerns about other institutes recruiting our REU students, so visits to multiple graduate schools are an important and valued part of the program.

Students are paid a fair stipend and housed on campus within a 5 minute walk of our academic building. Because we do not have extensive graduate student office space, we assign all eight students to a senior projects lab that is rearranged to resemble graduate student offices, issuing each student a computer and ample work space. Faculty offices are just feet away from the student offices, and faculty mentors are expected to be present nearly every day, all day, when the students are working.

Because RHIT is undergraduate focused, research conducted with REU students is valued by the institute and thus worthwhile for faculty. Although all of our faculty are involved in scholarly work, they are generally less encumbered with large research projects that could distract from REU mentoring. The faculty thus have more flexibility from one summer to the next in defining their work. In the EFRI REU, faculty are an active member of the research team, not directing student work, but reviewing student work and advising regularly to allow the team to be as efficient as possible. EFRI REU faculty will typically spend 10 hours per week mentoring a single project, and will contribute additional time to the REU by joining the students for lunch, sponsoring cookouts, accompanying the students on trips, and by simply making sure they are available when needed. This commitment of mentor time is partially acknowledged by a faculty stipend included in the EFRI REU budget.

"Proceedings of the 2005 American Society for Engineering Education Annual Conference \& Exposition Copyright . 2005, American Society for Engineering Education” 
Assessment data for the EFRI REU is limited since 2004 was its inaugural year. However, preliminary feedback from students and faculty has been positive. In every way, the program was more successful than hoped. Of the eight students in the program, four entered reporting a strong interest in graduate school, but seven of eight enthusiastically reported interest in graduate school by the end of the summer. All three projects have resulted in papers submitted to major journals. One project has already been presented at an international meeting. Though the time invested by faculty mentors was likely more than expected, all three faculty authors agree the time was well spent. The program is faced with two challenges to be sustainable: funding was not quite sufficient to cover all expenses and sincere commitment of faculty to be present all eight weeks is difficult with so many conferences and workshops in the summer months.

\section{Assessment for Successful REU Programs}

REU Program administrators must seek input from all stakeholders in the program: student participants, identifiable beneficiaries of student research, faculty/professional mentors, REU program administrators, institute leadership, and National Science Foundation. This only became obvious to the authors as the work reported herein progressed, and is currently not even incorporated into Rose-Hulman's own REU site assessment, described previously. To conduct this assessment, as a minimum, REU administrators should ask the stakeholders the following three questions:

1. How does the REU program fit within the stakeholder's mission?

2. What does the stakeholder consider to be positive aspects of the program with respect to their mission?

3. What would the stakeholder change to make it more beneficial to helping them meet their mission? How this assessment is conducted will vary from stakeholder to stakeholder.

In addressing these minimum assessment concerns, the student participants' assessment will likely be more extensive than these above three questions, but should include these three questions in some form. Students may not be prepared to identify their mission, and may need an activity during their REU helping them define their mission. Beneficiaries of student research will also likely be assessed in most REU programs, so the recommended three questions should be included in those assessments as well.

National Science Foundation stakeholders would likely be assessed through a simple interview format after program annual reports are filed. This could be problematic for NSF program administrators if many REU sites begin doing regular assessment of this type. We propose NSF should create an evaluation form for providing feedback to REU sites as part of the annualr report review process. This way, all REU sites will benefit from the input and be encouraged to improve.

Institute leadership is a crucial stakeholder in the programs, so although it may be unusual to query department heads, deans, and higher ranking institute officials about their satisfaction with a specific REU program, it would seem prudent for faculty to at least query their own institute leadership about REU programs in general. Similarly, assessment of faculty mentors would seem critical to determining not only how the program may be improved, but also whether those mentors may remain active in the program in subsequent years. As this study progressed, it

"Proceedings of the 2005 American Society for Engineering Education Annual Conference \& Exposition Copyright . 2005, American Society for Engineering Education” 
became more and more clear that the performance and satisfaction of these mentors could have the largest influence on student success.

The final stakeholder is the REU program administrator. Assessment of their own perspective on the three questions identified above would likely be best facilitated through a reflective summary prepared after reviewing the other assessment feedback.

As a part of this work in progress, RHIT's EFRI REU will develop additional assessment addressing the stakeholders' concerns, at least to the extent described herein. Upon completion, the findings of this additional assessment will at least be included in our report to NSF, but also will be submitted to the forum of this paper for possible presentation at a future ASEE Annual Meeting and Exposition.

\section{Conclusions}

Successful REU programs should focus on relationships, meaningful research, planned learning and creation of a community of learner/researchers. Contrary to common beliefs, undergraduatefocused institutes can provide superior REU experiences because the facilities, faculty, and infrastructure value and specialize in working with undergraduates. Traditional research institutes can also provide successful REU's, but these must be planned carefully so that all stakeholders value the program and are part of a win-win outcome. If this planning does not occur, the REU program may fail or will succeed at great personal cost to the PI and mentors involved. Assessment of all stakeholders is important for program improvement. When well administered, regularly assessed, and subject to continuous improvement, REU programs are an asset to the research community, allowing students who may not seriously consider a future in research to experience and examine research as a viable and desirable pursuit.

\section{Bibliography}

Block, P. (2000) Flawless Consulting, $2^{\text {nd }}$ Ed., Jossey-Bass/Pfeiffer, 372 pages.

Booth, W.; Colomb, G.; and Williams, J. (2003) The Craft of Research, $2^{\text {nd }}$ Ed., The University of Chicago Press, 329 pages.

Covey, S. (1989) The Seven Habits of Highly Successful People, Free Press, 360 pages.

Eisenman, S. and List, G. (2004) “The Undergraduate Research Advantage: The Split Perspective," Proceedings: ASEE Annual Conference and Exposition, Salt Lake City, Utah.

Kukreti, A.R. (2004) "Research Experiences for Undergraduate Students in Structural Engineering," Proceedings: ASEE Annual Conference and Exposition, Salt Lake City, Utah.

Lewis, G.L. (2003) Guidelines for Forensic Engineering Practice, American Society of Civil Engineers, 140 pages.

NSF (2004) Research Experiences for Undergraduates (REU) Supplements and Sites: Program Solicitation NSF 04584, National Science Foundation, Washington, D.C.

"Proceedings of the 2005 American Society for Engineering Education Annual Conference \& Exposition Copyright . 2005, American Society for Engineering Education” 


\section{Biographical Information}

KEVIN SUTTERER is an Associate Professor of Civil Engineering and Director of Rose-Hulman's Engineering Forensics Research Institute (EFRI). He is the principal investigator for an NSF REU site at Rose-Hulman and served as a mentor for two projects during the EFRI REU's inaugural 2004 program.

MARTIN BRENNY is a Senior Civil Engineering Student at Rose-Hulman. He participated in the EFRI REU Site during the Summer of 2004 and is currently investigating graduate school opportunities in civil engineering.

J. DAVID PIRNIA is a Senior Civil Engineering Student at Rose-Hulman. He participated in an off campus REU Site during the Summer of 2004 and is currently investigating graduate school opportunities in civil engineering.

Michelle WoOdWARD is a Senior Civil Engineering Student at Rose-Hulman. She participated in an off campus REU Site during the Summer of 2003 and is currently investigating graduate school opportunities in veterinary medicine.

Robert Houghtalen is a Professor of Civil Engineering and the CE Department Chair at Rose-Hulman. He was an assistant mentor for one EFRI REU project in the Summer of 2004 and a regular participant in and supporter of REU activities during the program.

JIM HANSON is an Assistant Professor of Civil Engineering at Rose-Hulman. He was a mentor for two EFRI REU projects in the Summer of 2004 and a regular participant in and supporter of REU activities during the program. 


\begin{tabular}{|c|c|}
\hline & Table 1 \\
\hline Adm & nistrative \\
\hline ○ & $\begin{array}{l}\text { A formal workshop or short course is beneficial to learning about more than just the } \\
\text { research, plus it is a good place to learn more about how to do the research correctly. }\end{array}$ \\
\hline O & $\begin{array}{l}\text { A regular pay schedule every two weeks or at least three different times as compared to } \\
\text { just one or two lump payments is preferred. }\end{array}$ \\
\hline ○ & $\begin{array}{l}\text { Training in group work is very helpful. Faculty mentors may also need to manage team } \\
\text { dynamics when one or several group members is having difficulty working with the team. }\end{array}$ \\
\hline ○ & $\begin{array}{l}\text { Exposure to the graduate school setting is very helpful. Trips to other graduate schools } \\
\text { shows how different they are in some ways, but also how similar in others. Such visits } \\
\text { also demonstrate similarities between REU students and those already in graduate school. }\end{array}$ \\
\hline ○ & $\begin{array}{l}\text { Field trips, though not more than one a week and more towards the beginning than the } \\
\text { end of an REU, are a real bonus in terms of seeing the real world and application of } \\
\text { research to real problems. }\end{array}$ \\
\hline O & $\begin{array}{l}\text { Activities should be scheduled in advance so students are not surprised at the last minute } \\
\text { and have to change other plans they have made. }\end{array}$ \\
\hline O & $\begin{array}{l}\text { There should be a required meeting schedule with faculty mentors and students, although } \\
\text { faculty mentors should be available at all times for quick assistance with the research and } \\
\text { learning process. }\end{array}$ \\
\hline ○ & $\begin{array}{l}\text { Facilities should include a common student work area and computer facilities so students } \\
\text { do not have to spend a lot of time or even all summer working all alone. }\end{array}$ \\
\hline O & $\begin{array}{l}\text { Programs should include education about resources that are available on campus, } \\
\text { including tours, presentations, and instructions on the use of those resources. }\end{array}$ \\
\hline Com & nunity \\
\hline & $\begin{array}{l}\text { Outside activities/community are as important as project work, even impacting work } \\
\text { ethic and motivation. These must be emphasized to improve the odds of success. }\end{array}$ \\
\hline O & $\begin{array}{l}\text { An early orientation dinner should be scheduled for all students in the college/institute } \\
\text { from different programs to get folks together and begin the process of building } \\
\text { community. }\end{array}$ \\
\hline ○ & $\begin{array}{l}\text { Contact with graduate students and other researchers must be encouraged and expected. } \\
\text { Students learn much from interacting with non faculty research personnel. }\end{array}$ \\
\hline O & $\begin{array}{l}\text { Arranged housing with students housed together is important. Students are unfamiliar } \\
\text { with campus and have no community to move to unless this is created in advance. }\end{array}$ \\
\hline ○ & $\begin{array}{l}\text { If there is not community of similar students on campus, students will likely have a more } \\
\text { difficult time. This should be considered in program development. }\end{array}$ \\
\hline ○ & Student orientation should include recreational opportunities, phone numbers, and maps. \\
\hline ○ & $\begin{array}{l}\text { Faculty must work harder to build community among students through outside activities } \\
\text { in the early days of the program, but then expect students to manage on their own later. }\end{array}$ \\
\hline ○ & $\begin{array}{l}\text { Getting to know the faculty families at the faculty's home is really beneficial and gives } \\
\text { the students a "normal" setting to spend a little time away from campus. }\end{array}$ \\
\hline ○ & $\begin{array}{l}\text { One local student in the REU program can be a real asset is that student is outgoing ansd } \\
\text { willing to answer a lot of questions and help with orientation. }\end{array}$ \\
\hline O & $\begin{array}{l}\text { Planned free activities like baseball game, trips, amusement park, camping, etc. are } \\
\text { important and worthwhile, though not likely to be a part of the NSF budget. }\end{array}$ \\
\hline $\mathrm{O}$ & Permit weekend and even extended weekend travel on at least a few occasions \\
\hline
\end{tabular}

"Proceedings of the 2005 American Society for Engineering Education Annual Conference \& Exposition Copyright . 2005, American Society for Engineering Education” 


\begin{tabular}{|c|c|}
\hline & able 1 (continued). Characteristics of Quality Programs based on Student Input \\
\hline Enric & hment \\
\hline O & $\begin{array}{l}\text { Field trips to work sites, labs, manufacturing facilities, fabrication shops, etc. are } \\
\text { appropriate, including sites or projects the students are studying }\end{array}$ \\
\hline O & Videotape student presentations so the students can improve. \\
\hline ○ & Creating a "mini thesis" can give students confidence they can do a thesis too. \\
\hline & $\begin{array}{l}\text { Students should understand their work is valued, either through potential for publication } \\
\text { or through other valuing factors, such as appreciative clients. }\end{array}$ \\
\hline & $\begin{array}{l}\text { Schedule special guest lectures (and faculty lectures) and various professional, academic, } \\
\text { and practice-oriented topics, including case studies. }\end{array}$ \\
\hline ○ & Outreach to high school students or other students can be rewarding \\
\hline Proje & ct Structure \\
\hline O & Advance planning of projects by faculty mentors is very important. \\
\hline & Advance project descriptions are helpful in evaluating REU before acceptance \\
\hline & $\begin{array}{l}\text { Clear description of program structure in advance of application should be standard for } \\
\text { all REU's. }\end{array}$ \\
\hline O & Students consider being able to select a project a bonus. \\
\hline & $\begin{array}{l}\text { Students must be allowed to work independently, but have faculty available to assist } \\
\text { when needed. }\end{array}$ \\
\hline & $\begin{array}{l}\text { Students need to become comfortable that they are not alone. They must know that help } \\
\text { is available nearby when they get under stress. Comfortable early rapport with faculty } \\
\text { advisors and/or groups is important. }\end{array}$ \\
\hline O & Preparation in advance by mentors is necessary for a fast start. \\
\hline o & Avoid student down time. Keep students challenged. \\
\hline O & Students must have a final project to show and do a final presentation. \\
\hline ○ & Faculty commitment to the project is crucial. \\
\hline O & $\begin{array}{l}\text { If there are outside clients, they must be engaged and helpful. Clients can delay progress } \\
\text { of a project. }\end{array}$ \\
\hline O & Multidisciplinary teams demand planning of multidisciplinary work in the project. \\
\hline O & Students must believe in project completion regardless of its difficulty. \\
\hline ○ & Open ended work and decision-making on the research by the students is good. \\
\hline & $\begin{array}{l}\text { Set up intermediate work submittals, but be flexible. The goal should be to avoid an end } \\
\text { of summer pileup. }\end{array}$ \\
\hline & Critique, but do not grade projects. Faculty mentors are part of team, not the teachers. \\
\hline
\end{tabular}

"Proceedings of the 2005 American Society for Engineering Education Annual Conference \& Exposition Copyright . 2005, American Society for Engineering Education” 